\title{
Parental Upbringing Styles and Their Relationship with Social Withdrawal Among A Sample of Kindergarten Children: The Forgotten Victim
}

\author{
Intisar Turki ALdarabah \\ Associate. Prof., Early Childhood, Faculty of Education, Al-Hussein Bin Talal University, Jordan \\ Reham Almohtadi \\ Associate. Prof., Early Childhood, Faculty of Education, Al-Hussein Bin Talal University, Jordan \\ Mustafa Jwaifell \\ Associate. Prof., Instructional Technology, Faculty of Education, Al-Hussein Bin Talal University, Jordan, \\ Fahima Dib \\ Assistane Prof., Education, Faculty of Education, Ali Lounissi-Blida2, Algeria
}

\begin{abstract}
This study aimed to find out the paternal treatment styles and their relationship with social withdrawal among children whose ages ranged between (4-6) years old. The study sample consisted of (50) male and female children attending Al-Lo'Lo Al-dori Kindergarten in Ma'an City. The analytical method is used to determine aspects of parents' behavior and aspects of the social withdrawal behavior that formulate the study instrument. The descriptive correlation method is also used to determine the relationship between variables. Results showed that there are differences with statistical significance between parental treatment styles represented in rejection styles, authorization, and over protection; and the social withdrawal, since over protection has occupied the highest level. Also, there are differences with statistical significance between parental treatment styles and gender. Results showed that the level of social withdrawal is high among kindergarten children; especially among males more than females under the same category of social withdrawal. Direct correlation is also found between parental treatment method and social withdrawal.
\end{abstract}

Keywords: Parental Treatment, Social Withdrawal, the Forgotten Victim, Kindergarten's Child.

DOI: $10.7176 / \mathrm{JEP} / 10-18-10$

Publication date:June $30^{\text {th }} 2019$

\section{Introduction}

Childhood stage is considered as one of the most important stages through the growth of the child's personality and his psychological consistency. Since there is a strong relation between the individual's personality and his psychological health, personality integration is important for psychological health and social consistency. Factors that hinder personality integration and psychological health include conscious and unconscious severe psychological struggles which deprive personality its unity and balance, leading it to disintegration (Al-Mahdi, 2002). Some studies have confirmed that childhood years are the base in forming appropriate and consistent personality.

As a result, if childhood years were appropriately constructed, the individual will be more mature and productive during adolescence and adulthood stages, vice versa is also true (Abdalal, 2003). Al-Niyal, (2002) shows that parental treatment styles influence the psychological and social formation of children, so if parents use destructive styles (include feelings of fear disconfidence), children will suffer psychological and social disorder. Whereas, if constructive styles were used (accompanied by understanding and intimacy), children will enjoy a healthier psychological state.

Social isolation is one aspect of the human behavior's aspects and one of the developmental problems that children suffer from, which shows the individual's inability to engage in social relationships and becoming more self-centered (Al-Azza, et al, 2001). Peterson et al, (2002) have identified withdrawal behavior as referring to those children who feel lonely, so they are not helped by others to face their problems, their attitudes are not supported by anyone of their surrounding people, they are unable to face the difficulties, and finally they suffer low self-esteem One of the social withdrawal aspects as mentioned by Kamal (2002) are shame, day dreaming, anxiety, introversion, fear of establishing relationships, self-unawareness and perception, slow and stuttering in speaking, and feeling of infirmity.

\section{Statement of the Problem}

The study problem stems from being one of the problems that crossed the countries national borders. Some of 
child maltreatment forms can be culturally and socially attributed to some of the wrong practices and beliefs which might be confusing when distinguishing between upbringing methods and discipline. As a result, some of the hidden crimes become socially accepted such as girls early marriage or the severe physical punishment of children. Therefore, if such behaviors are not treated and overcome early, they will lead to behavioral, psychological, social and emotional disorders in the child, such as the appearance of aggressive behavior, introversion, isolation, and low academic achievement. This is assured by Carolle, (1990) study that children who received bad care from their families at the childhood stage were characterized by isolation, aggressiveness, weak concentration, and lack of considering other's feelings. Studies indicate that $(10 \%)$ of school age children suffer from social isolation and $(30 \%)$ of the 4 to 6 years old children suffer from social isolation.

\section{Questions of the study:}

1) What is level of the parental treatment styles kindergarten's children?

2) Do parental treatment styles differ among male and female kindergarten's children?

3) What is the level of the social withdrawal among kindergarten's children?

4) Dose the level of social withdrawal differ between male and female kindergarten's children?

5) Is social withdrawal predictable among the kindergarten's children through the levels of parental treatment styles (rejection, discrimination, authorization, neglect and over protection)?

\section{Objectives of the Study:}

1. To reveal the relationship between parental treatment styles and the social withdrawal of (4-6) year-old children.

2. To measure the differences between children regarding parental treatment styles according to gender.

3. To identify the levels of social withdrawal among children according to gender.

\section{Significance of the Study}

Significance of the study is represented in finding out the different forms of parental treatment styles towards children that might be harmful to the child's health, development, behavior, and personality and self. On the practical side, it helps in employing the study results for family counseling through enlightening fathers and mothers about the parental treatment styles and their influence on kindergarten's children. Results also contribute to helping professionals in introducing a list of appropriate and wrong treatment styles in addition to the effect of each style on the child. It also helps the kindergarten's female teachers realize the children's behavioral, emotional and personality disorders and know how to treat them.

\section{Theoretical Frame and Literature Review}

Researchers have disagreed about determining the concept of maltreating kindergarten's children. This ambiguity surrounding the concept is due to its being a cultural and social concept, so it changes according to the social and cultural changing of the environment. World Health Organization (WHO) identified it as bearing all negative forms of physical or emotional care, by hurting, neglecting, carelessness, or money exploitation, causing actual or potential harm to the child's health and life (Marcelli, 2006).

Hazen, (2006) study confirmed that parents' violence against children is usually accompanied with behavioral disorders on the part of the son towards the self and others. Some parents practice with their children the same treatment they had received during their childhood stage (Hetherngton, 1978). These styles are different from each other although they are interrelated in that one style might be the beginning for the occurrence of other styles. Some of these styles are:

1. the authoritarian style: It means the continuous prevention and rejection of the child's desires, even if they are appropriate and legal.

This style leads to negative results, including the child's weak personality, lack of self-trust, feeling inferior, and the fear from authority (Mehrez, 2005). This style is characterized by low emotional warmth degree.

2. Over protection style: It appears in the over fear about the child from any risk that might threaten him. This fear delays the child's self-dependence, especially if the child is the first or the only in the family, they exaggerate in upbringing him (Mosallamani, 2009).

This style deprives the child from forming successful relations, having self-confidence, and enjoying good motivation for achievements.

3. the Rejection Styles:

Rejection style is considered as one of the inappropriate styles in upbringing sons, since parents or one of them use styles including hatred, dissatisfying his needs, lack of warmth, threatening him to get out of the house, and humiliating him through different forms in front of his peers, which pushes him to aggression (Al-Thaher, 2004). 


\section{Discrimination in The Treatment Style}

It includes preference, bias, and inequality among the sons with regard to care and attention, by showing greater love to the older son or the younger son, preferring the males over the females, or giving one of the sons a sense of priority, financial or moral incentives and privileges more than the rest of his siblings (Mehrez, 2005).

\section{Neglecting Style}

It is one of the popular styles in children's maltreating field, and it indicates a failure or defect in providing the children with the basic needs, such as food and housing. So, the neglected child feels that he is undesired, and he does not receive his right to have a place within the social system, this feeling generates in him the resistance and tendency to withdraw from the social life (Engler, 2006). The socially withdrawn child is usually perceived as a source of risk for himself not on the surrounding others, he does not make problems or noise inside the family or the school. He is often described by his teacher as a child who is unable to communicate, and usually fails in school activities. Some of them return to early stages of development and ask for the help of others (Kauffman \&Hallhan, 1991).There are a number of theories to explain the withdrawal behavior:

First: Psycho Analytical Theory: Freud contends that social withdrawal pertains to the early childhood stage, since the first five years with the experiences the child faces at this stage affects his personality in the future. In the light of this (Mohammad, 2002) sees that the roots for isolation at older stage begin in childhood, and the individual before adolescence needs a friend to exchange information with. Children who lack the social skills because of the wrong interaction with their parents during childhood makes it difficult for them to have friends later on.

Second: Erick Erikson: Erikson sees that the psychological tension resides in the weak ego, and the individual's inability to perform his functions. If tension continues in a dissatisfactory manner, this will lead to weak self-trust, and lack of psychological security which might cause some emotional disorders such as isolation and keeping away from sources of psychological tension (Al-ta'I, 2003).

Third: Horney's Theory: When the individual fails in his attempts to receive the warmth and the saturating relationships from the surrounding people, he isolates himself and rejects to connect with them. He does not accept help from others, and never shows his problems to them (Kafafi, 1989).

Fourth: Karl Roger's Self-Theory: It asserts that the correspondence between the self and the experience leads to appropriate experience coding, while the incompatibility between them leads to inaccurate coding resulting in psychological maladaptation. Rogers asserts the need for belonging, friendship, positive interest in the individual, love of others, empathy, appreciation and respect (Al-Khawaja, 2002).

\section{Literature Review}

Badr Al-deen (2015) study aimed to know the relationship between parental upbringing style and the early detection of learning difficulties in a pre-school child. The study was applied on a sample of Egyptian families in Qina City to know the used parental treatment style, and the extent of family awareness as well as their interest in exploring and treating their children's learning difficulties. Results showed that there was a relation between parental treatment style (positive and negative) and the early detection of learning difficulties at early stages.

Results also showed that positive treatment styles and the resulting behavioral and verbal interaction between the parents and the child can help in early disclosure of learning difficulties.

Mansour's (2010) study aimed to find out the predicted parental treatment styles of some of the behavioral problems of kindergarten's children in The Kingdom of Bahrain. The sample consisted of (34) children aged between (10-13) years old. Results indicated that the sample's individual degrees on parental treatment styles scale as perceived by the sons in relation to the father predicted some of the behavioral modes such as the impulsive behavior, anxiety, and fear. It also showed that the predicted modes when sons are related to mothers are anxiety, fear, and an increasing possibility of the appearance of withdrawal behavioral modes.

Mohi Al-deen's (2004) study aimed to know parental treatment styles as perceived by the parents and problems of the emotional and social adjustment of the pre-school children. The study sample consisted of (155) fathers and mothers who were randomly selected. Results showed that there was a difference between the parental treatment and the emotional social adjustment only on the quality dimension, whereas differences are not recognized when gender is considered..

Hane; Ashley \& Charrise (2008) study aimed to reveal the impact of the mother's behavior on shyness and the withdrawal behavior at the middle childhood stage. The study sample consisted of (80) students from the intermediate stage. Results showed that the level of social withdrawal was at medium degree, and the registered shyness was an important predictive factor for the social withdrawal of the child.

(Enns, 2008) study revealed the effect of the exposure to slapping during the childhood stage along with social withdrawal on the relationship between the mother and the child, in addition to the mother's expression of emotions and the social skills development. The study sample consisted of (49) pairs of mothers and children 
aged around (9-12) years old. Results showed that social withdrawal level among the study sample individuals was high, and history of the mother in social withdrawal is an important predictive factor for the child to develop this kind of behavior.

Sam'an's (2010) study aimed to know the social withdrawal among the mentally-retarded children and its relationship with some variables (wrong parental treatment, degree of retardation and gender) in Damascus City. Results showed that correlation coefficient value between social withdrawal of the mentally-retarded children and the wrong parental treatment equal (0.58), which means withdrawal severity increases with the increase in the wrong treatment styles. The correlation coefficient value between social withdrawal and gender equal $(0.15)$, which reflects the presence of weak influence of gender on social withdrawal.

\section{Study population and sample}

Study population consisted of the kindergarten's children in Ma'an city. The study sample consisted of (50) male and female children whose ages ranged between (4-6) years old, and were randomly selected from two branches of the kindergarten's children (Al-Lolo Al-dorri).

\section{Methodology of the study}

Analytical method is used to determine behavior aspects of the parents and social withdrawal aspects to formulate the study instrument, and the correlative descriptive method is also used to determine the relationship between the variables.

\section{Research instruments:}

1. Parental treatment styles scale as perceived by the sons (Ahmad, 2001).

2. Children's social withdrawal scale (Mohammad, 2002).

Validity of the research's instruments:

The study's two instruments have been introduced to a group of arbiters, application and re-application by the same female teacher to calculate stability of the analysis using (Holsti) equation, and calculating number of agreement and number of disagreement to confirm stability of the analysis which reached (0.867) to measure parental treatment styles, and (0.93) for social withdrawal scale which can be considered high stability and acceptable percentages for purposes applying the study.

Table (1) Distribution of the Study's Two Scales Degrees

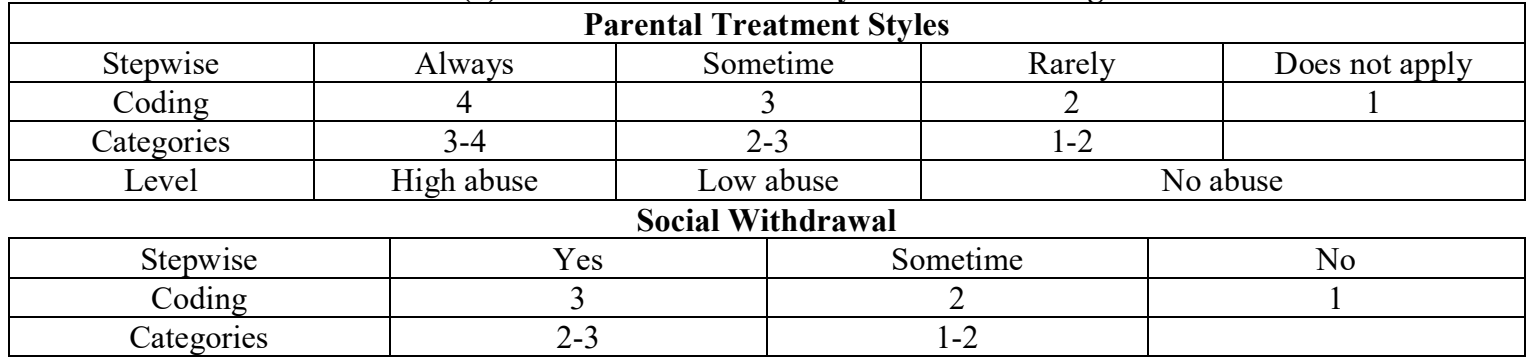

\section{Reliability of the Study's Instruments}

The study instruments were applied and re-applied by the female supervisor teachers on the students after two weeks of the first application, in addition to calculating correlation coefficients between the first application of parental treatment styles' scale for each dimension, and correlation coefficients between the dimensions and the scale as a whole. Whereas, for the social withdrawal scale, internal consistency coefficient has been calculated through Cronbach's Alpha, its value reached (0.607) with statistical significance at level $(\propto \leq 0.05)$, while person's stability coefficient reached by re-application $(0.974)$, which is a very high value and relevant for the study purposes.

Table (2) Pearson's Stability Coefficients for Parental Treatment Styles Scale

\begin{tabular}{|c|c|c|c|}
\hline Parental treatment styles & Number of the clauses & Byre-application & The dimension with the total \\
\hline Rejection & 5 & $.986^{* *}$ & $.465^{* *}$ \\
\hline Discrimination & 5 & $.963^{* *}$ & $.547^{* *}$ \\
\hline Authoritarian & 7 & $.979^{* *}$ & $.647^{* *}$ \\
\hline Over protection & 5 & $.913^{* *}$ & $.514^{* *}$ \\
\hline Neglect & 6 & $.927^{* *}$ & $.326^{* *}$ \\
\hline Total & 28 & $.932^{* *}$ & \\
\hline
\end{tabular}

** Correlation is significant at the 0.01 level, $* 0.05$ 
Results of the Study and Discussion

Results related to the first question: What is level of parental treatment styles of kindergarten's children)? To determine the level of parental treatment styles for the kindergarten's children, means and standard deviations were calculated as follows:

Table (3) Means and Standard Deviation for Parental Treatment Styles $(\mathrm{N}=\mathbf{5 0}, \mathbf{d f}=\mathbf{4 9})$

\begin{tabular}{|c|c|c|c|c|c|c|c|c|}
\hline Treatment styles & $\begin{array}{c}\text { Number of } \\
\text { the clauses }\end{array}$ & Mean & Std & Rank & Level & $\begin{array}{c}\text { Crucial } \\
\text { scare }\end{array}$ & T value & Sig. \\
\hline Rejection & 5 & 2.43 & 0.52 & 3 & Low & 2 & 5.796 & 0.000 \\
\hline Discrimination & 5 & 2.09 & 0.43 & 5 & & & 1.435 & .158 \\
\hline Authoritarian & 7 & 2.42 & 0.39 & 4 & & & 7.701 & 0.000 \\
\hline Over protection & 5 & 3.17 & 0.48 & 1 & High & 3 & 2.464 & 0.17 \\
\hline Neglect & 6 & 2.47 & 0.39 & 2 & Low & 2 & 8.473 & 0.000 \\
\hline Total & 28 & 2.51 & 0.28 & - & Low & 2 & 12.694 & 0.000 \\
\hline
\end{tabular}

Results of one sample test show the rank of each style of the parental treatment styles:

1) All of the parental treatment styles fall at low abuse level with statically significance, except parental treatment style regarding discrimination which falls at the level of the absence of abuse.

2) Parental treatment style regarding over protection occupies the highest level.

Oates, (1996) showed that abusing parental treatment styles lead those sons to show over shyness, fear from strangers, disturbed social relationships with peers, and undesired social behaviors like withdrawal from social activities.

Over protection style in treatment is one of the negative styles based on exaggeration in protecting and caring for the child. Parents in this case deprive the child of the opportunities that help him learn and become self-dependent in holding responsibility.

All this is attributed to over anxiety and fear for their sons. Therefore, the effect of over protection style can be touched in children's attachment to their parents and inability to mature emotionally, in addition to their dependency and lack of social and psychological consistency.

Most of the results indicate that parent's personality and their upbringing style have a great relationship with the sons' personality. Parents also have several styles of behavior toward their sons in life situation inside or outside the house (Al-Soofi\& Al-Malki 2012).

These results can be attributed to over protection style which deprives the child of his desire to be independent since continuous intervening in his affairs does not give him the opportunity to select his different activities, and he finds it difficult to hold responsibility especially in the future which influences his thinking style. This model influences the child's integrated growth, and the rise of ego-centered and procession level (Hammood, 2010). This will lead to the lack of self-confidence, inability to continue learning and holding responsibility, and being deprived of having the opportunity to learn from mistakes (Abdeen, 2010).

Over protection might lead to preventing children from playing and engage with others because of fear for them, then the child feels unable to construct social relationships which makes him dissatisfied with the self and others (Al-Sabawi, 2010). This result agrees with Mansour's (2010) study and MohiAldeen's (2004) study.

Results related to the second question: Do parental treatment styles differ among male and female kindergarten's children?

Means of parental treatment styles levels were calculated according to gender, and an independent sample T-test was conducted as seen in table (4): 
Table (4)Means and Standard Deviations of Parental Treatment Styles for gender variable (Males= 23, Females $=27$ )

\begin{tabular}{|c|c|c|c|c|c|c|}
\hline Treatment styles & Gender & Mean & Std & Level & $\mathrm{T}$ value & Sig. \\
\hline \multirow{2}{*}{ Rejection } & Males & 2.68 & 0.46 & \multirow{2}{*}{ Low } & \multirow{2}{*}{3.460} & \multirow{2}{*}{.001} \\
\hline & Females & 2.21 & 0.48 & & & \\
\hline \multirow{2}{*}{ Discrimination } & Males & 2.35 & 0.34 & \multirow{2}{*}{ Does not exists } & \multirow{2}{*}{4.667} & \multirow{2}{*}{.000} \\
\hline & Females & 1.87 & 0.34 & & & \\
\hline \multirow{2}{*}{ Authoritarian } & Males & 2.64 & 0.34 & \multirow{2}{*}{ Low } & \multirow{2}{*}{4.227} & \multirow{2}{*}{.000} \\
\hline & Females & 2.24 & 0.33 & & & \\
\hline \multirow{2}{*}{ Over protection } & Males & 3.34 & 0.40 & \multirow{2}{*}{ High } & \multirow{2}{*}{2.430} & \multirow{2}{*}{.019} \\
\hline & Females & 3.02 & 0.51 & & & \\
\hline \multirow{2}{*}{ Neglection } & Males & 2.59 & 0.38 & \multirow{2}{*}{ Low } & \multirow{2}{*}{2.141} & \multirow{2}{*}{.37} \\
\hline & Females & 2.36 & 0.38 & & & \\
\hline \multirow{2}{*}{ Total } & Males & 2.71 & 0.19 & \multirow{2}{*}{ Low } & \multirow{2}{*}{6.223} & \multirow{2}{*}{.000} \\
\hline & Females & 2.33 & 0.23 & & & \\
\hline
\end{tabular}

Results of T-test for the independent samples show:

1) Rejection, authoritarian, neglect, total of parental treatment: Both male and female kindergarten children are subject to low level parental treatment abuse, while males are subject to more parental treatment abuse than females with statistical significance.

2) Discrimination: Female kindergarten's children do not feel parental treatment abuse style regarding discrimination dimension, while males feel low level of abuse.

3) Over protection: Both male and female kindergarten's children are subject to high level of over protection as a style of parental treatment, but T-test results showed that males are subject to more over protection than female. From a cultural perspective, males should be raised according to masculinity patterns preparing them to face harsh life conditions. Therefore, males behavior sometimes push parents to abuse them. In contrast, females are educated differently by parents because of their obedience and calm attitude. This result disagrees with MohiAl-deen's (2004) study.

Results related to the third question: What is the level of the social withdrawal among kindergarten's children?

To determine the level of social withdrawal among the kindergarten's children, calculated means and standard deviations were extracted from the study's second instrument, since the mean for social withdrawal reached (2.55) with standard deviation (0.35) at high level of social withdrawal T-test for one sample by (49) freedom degree, T-value reached (11.196) with statistically significance at level $(\propto<0.05)$. So, the level of the social withdrawal is high among the kindergarten's children.

It is possible to explain this result by considering the withdrawal style as a define means that child resort to unconsciously to mitigate the pain and the stress severity he feels. This withdrawal makes them socially unmature and causes delay for them compared to those of the same age (Yousef, 2011). Reasons for pushing the child to social withdrawal include peers group, the family, and the media. The child who does not consider himself a source of the group's admiration will be ready for developing a withdrawal feeling. Also the relationships between parents and the child contribute to the rise in the withdrawal level, since for example a relation based on over protection will create a selfish personality characterized by weak self-trust. The media also plays an important role in the aspect of withdrawal through refluxing multiple forms of social and relationship problems in attractive ways to the children's attention, leaving great influence on the individual's behavior, in addition to the lack of support and encouragement for their social behaviors.

Upbringing style based on inconsistency might lead to the withdrawal behavior. Also some children might be isolated only at home; such children spend a lot of time searching for completely stable individuals to deal with them, this result agrees with Enns, (2008) study.

Results related to the fourth question: Does the level of social withdrawal differ between male and female kindergarten's children?

Means and standard deviations were calculated for parental treatment styles level of the kindergarten's children according to gender variable, and conducted (independent sample T-test) as seen in the below table. 
Table (5) Means and Standard Deviation for Social Withdrawal According to gender variable

\begin{tabular}{|c|c|c|c|c|c|c|c|}
\hline Gender & No. & Mean & Std & Level & Df & T value & Sig. \\
\hline Males & 23 & 2.76 & .16 & \multirow{2}{*}{ High } & \multirow{2}{*}{48} & \multirow{2}{*}{4.469} & \multirow{2}{*}{.000} \\
\hline Females & 27 & 2.38 & .38 & & & \\
\hline
\end{tabular}

The table above shows that the level of social withdrawal among males and females is high, while mean of social withdrawal for the male children is higher than in the case of females. T-tests showed the presence of statistically significance at level $(\propto<0.05)$, so the level of the social withdrawal among the males is higher than in case of females but at the same category of the social withdrawal. This result might be attributed to a number of factors:

First: Using electronic games to the extent that every center must have games corner, even each home has electronic games, which makes them available to everyone especially for the children encouraged by their parents or their peers to use them (Krogh, 2001).

This result agrees with Salem's (2015) study that electronic games work on reducing the practice of social activities which leads children to neglect developing friendships because of their over use of electronic games. A relation has been found between social isolation variable among pre-school children and the number of playing hours with electronic games, the difference was in favor of the male children.

Second: Nature of the society (religious commitment, preventing the mix between children).

Results related to the fifth question: is it possible to predict the level of social withdrawal among the kindergarten's children through levels of parental treatment (rejection, discrimination, over protection, authoritarian, and neglect)?

Means and standard deviations were calculated for degrees of parental treatment styles and social withdrawal among the kindergarten's children as seen in table (6).

Table (6): Means and Standard Deviation for the parental treatment styles and social withdrawal

\begin{tabular}{|c|c|c|c|c|c|c|}
\hline $\begin{array}{c}\text { Social } \\
\text { withdrawal } \\
\text { Y }\end{array}$ & $\begin{array}{c}\text { Neglect } \\
\text { X5 }\end{array}$ & $\begin{array}{c}\text { Over } \\
\text { protection } \\
\text { X4 }\end{array}$ & $\begin{array}{c}\text { Authoritarian } \\
\text { X3 }\end{array}$ & $\begin{array}{c}\text { Discrimination } \\
\text { X2 }\end{array}$ & $\begin{array}{c}\text { Rejection } \\
\text { X1 }\end{array}$ & \\
\hline 2.55 & 2.47 & 3.17 & 2.42 & 2.09 & 2.3 & Mean \\
\hline 0.35 & 0.39 & 0.48 & 0.39 & 0.43 & 0.52 & Std \\
\hline & .577 & .550 & .345 & .460 & .458 & Correlation \\
\hline & .000 & .007 & .000 & .000 & .000 & Sig. \\
\hline
\end{tabular}

Table (6) shows significance of Pearson correlation coefficient between parental treatment styles and social withdrawal, and the presence of Positive correlation, so the multiple regression analysis is used by (Enter) method.

Table (7): Summary of the used model.

\begin{tabular}{|c|c|c|c|c|}
\hline Model & R & R-Square & Adjusted R-Square & Std. Error of the Estimate \\
\hline 1 & 0.751 & 0.564 & 0.515 & 0.42339 \\
\hline
\end{tabular}

The table shows that $\mathrm{R}^{2}$ value indicates how much of the total variation in the dependent variable social withdrawal can be explained by the independent variables (Neglect, over protection, discrimination, authoritarianism). In this case, $51.5 \%$ can be explained, which is high.

To test null hypothesis: no linear relationship between the variables on the social withdrawal. analysis is used as shown in the following table:

Table (8): Results of ANOVA

\begin{tabular}{|c|c|c|c|c|c|}
\hline Source of variance & Sum of squares & df & Mean square & F & Sig. \\
\hline Regression & 3.378 & 5 & 0.676 & 11.405 & 0.000 \\
\hline Residual & 2.606 & 4 & 0.059 & & \\
\hline Total & 5.984 & 49 & & & \\
\hline
\end{tabular}

F-test showed that $\mathrm{F}=11.405$, the test is highly significant, thus we can assume that there is a linear relationship between the variables in our model, which indicates that the regression model predicts the dependent variable significantly well, where $\mathrm{P}<0.000$, which is less than $(0.05)$, and overall indicates that the regression model is statistically significant in predicting social withdrawal variable.

To predict social withdrawal from parental treatment styles: discrimination, over protection and authoritarianism, coefficients in the table provide the information. 
Table (8): Regression Summary

\begin{tabular}{|c|c|c|c|c|c|}
\hline \multirow{2}{*}{ Model } & \multicolumn{2}{|c|}{ Un standardized coefficient } & standardized coefficient & \multirow{2}{*}{ Sign } \\
\cline { 2 - 5 } & $\mathrm{B}$ & $\mathrm{SE}$ & Beta & & \\
\hline Constant & 0.194 & 0.332 & & 0.584 & 0.562 \\
\hline X1 Rejection & 0.146 & 0.072 & 0.217 & 2.015 & 0.050 \\
\hline X2 Discrimination & 0.080 & 0.098 & 0.099 & 0.817 & 0.418 \\
\hline X3 Authoritarianism & 0.195 & 0.099 & 0.217 & 1.961 & 0.056 \\
\hline Over protection & 0.190 & 0.088 & 0.262 & 2.148 & 0.037 \\
\hline Neglect & 0.310 & 0.102 & 0.148 & 3.048 & 0.004 \\
\hline
\end{tabular}

Based on the regression results we can infer the significance of parental treatment styles at level $(\propto \leq 0.05)$, rejection style was statistically significant $(\mathrm{T}=2.015, \mathrm{P}=0.05)$, Discrimination style was not statistically significant $(\mathrm{T}=0.817, \mathrm{P}=0.418)$, Authoritarianism was statistically significant $(\mathrm{T}=1.961, \mathrm{P}=0.056)$, over protection style was statistically significant $(\mathrm{T}=2.148, \mathrm{P}=0.037)$, Neglect style was statistically significant $(\mathrm{T}=$ 3.048, $\mathrm{P}=0.004)$.

Using the unstandardized coefficient values of $(\mathrm{B})$, the regression equation will be:

Social withdrawal $=(0.194+0.146)$, rejection style $+(0.08$, discrimination style $)+(0.195$ authoritarianism style $)+($ over protection style $)+0.31$ neglect style $)$.

Results of this study agree with Hane, Ashley \& Charrise\& Fox, (2008) study, Enns, 2008) study, and Sam'an, (2010) study.

Since severity of social withdrawal increases with the increase of wrong parental styles, the child whose parents (one of them or both) mistreat him, will not develop self-confidence and self-concept, his abilities will not grow, will have insufficient and inappropriate social skills, and will live within a family where bad relations are prevailing. Anxious relations and wrong treatment styles push the child's ego to create an imaginary world instead of the real one. If the child indulges in this world escaping from his painful reality, this will lead to a social withdrawal and isolation from others.

Also, parental wrong treatment means that parents reject the child, and whether this rejection is intentional or not, this will push him to withdraw to the imaginary, dreamy and wishful world. The rejection might also appear in the form of parents hatred, neglect, or authoritarianism against the child. Studies have asserted that the child in these cases inclines to social withdrawal.

\section{Recommendations and Suggestions}

1. Satisfying the child's needs to the level of acceptance since it is one of the child's most important psychological and emotional needs.

2. Not to deprive the child of discovery, experimentation and experience acquisition pleasure which raises his ability to face challenges and difficulties away from success seduction and avoid being crippled by failure.

3. Disseminating the awareness about the phenomenon of parental mistreatment styles and their impact on children and society through the different media.

\section{References}

Abdalal, S. (2003). Effectiveness of the Social Support from the Peers and the Older Individuals in Reducing the Child's Isolation Behavior.(Unpublished Doctoral Dissertation). Al-Zaqazeeq University, Egypt.

Abdeen, M. (2010). Parental Attitudes in the Youths, Social Upbringing As Perceived by The Second Secondary Students in South of the Western Bank/ Palestine. Jordanian Journal in The Educational Sciences, (6). (2): 129-146.

Al-Azza, S and Abdalhadi, J. (2001). Psychological Counseling, Its Methods and Techniques, Dar Al-Thaqafa, Amman, Jordan.

Al-Mahdi, S. (2002). Some Problems of the University Stage Female Students in Egypt and Saudi Arabia. Future of the Arab Education, (7), (20): 129-163, Egypt: Arab Center For Education and Development.

Al-Niyal, M. (2002). Social Upbringing: Alexandria, Dar Al-Ma'rifa Al-Jamiya.

Al-Sabawi, F. (2010). Social Shyness and its Relation with the Parental Treatment Styles. Dar Al-Safa For Publication, Amman - Jordan.

Al-Soofi, A \& Al-Malki, F. (2012). Bullying in the Children and its Relation with Parental Treatment Styles. Journal of Educational and Psychological Researches. (35): 146-188.

Al-Thaher, K. (2004). Behavior Modification, Dar Wael For Publication and Distribution, Amman, Jordan.

Badr Al-deen, K. (2015). The relation between the parental treatment styles and the early detection of the learning difficulties of the pre-school child. Journal of Educational and psychological studies/ Sultan Qaboos University, (9),3, 591- 606. 
Carolle, H. (1990). Can the age of entry in child care and the quality of child -care. prediet adjustment in Kindergarten, Development psychology, U. S.A ,126, (2), 294-305.

Engler, B.(2006). Personality theories: An introduction (7th ed). Boston: Houghton Mifflin company.

Enns,L (2008). Emotion Behaviors in Mothers With Childhood Histories of Aggression and / or Social Withdrawal and their children: An Inter Generational, High-risk study. (Unpublished of Dissertation of Master), Concordia University, Montreal, Canada.

Finn, J. (1989). Withdrawal from School, Review of Educational Research, 59 (2): 117-142.

Gaudn, J. (1993), Child Neglect, National center on child Abuse and Neglect, Ireland, Timothy.

Hallahan, D \& Kauffman 'J. (1991). Exceptional Children: Introduction to special education. (5th Ed). Prentic. Hall Inc, Englewood cliffs, New Jersey.

Hane, A, Ashley, G, Charrisa, R, fox, N. (2008). The Role of Maternal Behavior in the Relation Between Shyness and Social Reticence in Early Childhood and Social Withdrawal in Middle Childhood Social Development, 17(4):795-811.

Hazen, A., et.al (2006) Female caregivers experiences with intimate partner violence and behavior problems in children investigated as victims of maltreatment, Pediatrics, 117(1),.99-109.

Hetherngton, M. E., and Parke, R.D. (1978). Child psychology A contemporary view point, McGraw Hill Int. Book company, London.

Kamal, S. (2002).Encyclopedia of Special Education and Psychological Habilitation. Dar Al-Kitab Al-Arabi, Al-Ain, U.A.E.

Krogh, S, k, Slentz (2001).The Early Childhood Curriculum. New Jersey: Lawrence Erlbaum associates Inc publishers

Mansour, M. (2010). Parental Treatment Styles Predicting Some of the Behavioral Problems Among a Sample of Kindergarten's Children in Kingdom of Bahrain. Psychological Studies,. (21), (1): 99-135.

Marcelli. D, (2006), Enface et psychopathologie, Masson, Paris .

Mehrez, N. (2005). Parental Treatment Styles and Their Relation with The Child's Social and Personal Adjustment in the Kindergarten.Journal of Damascus University, (12), (1): 285-324.

Mohammad, A. (2002). Withdrawal Behavior Scale For (The Normal and Those with Special Needs). Dar Rashad: Cairo, Egypt.

Mohammad, A. (2002).Some of the Psychological Characteristics Related with Social Isolation among the University Youths, Dar Al-Rashad For Publication, Cairo, Egypt.

MohiAldeen, Kh. (2004). Parental Treatment Styles As Perceived by the Fathers and Emotinal and Social Consistency Problems of Pre-school children. Faculty of Education, The African University.

Mosallamani, S. (2009). Socio- Educational Science, Alexandria: Dar Al-Ma'rifa Al-Jamiya.

Oates, R (1996). The Spectrum of child Abuse Assessment, Treatment and Prevention. New York: Brunner Mazel, Inc.

Peterson .C.M. et al.(2002). Contra Living isolation issues university of Minnesota extension service number 983.WWW.extension umm. Edainfr familiers.

Reeve, J .(2001). Understanding motivation and emotion (3rd ed). Forth worth : Harcourt.

Salem, I. (2015) Electronic Games and their Relation with Social Isolation of the Kindergarten's children. Journal of the Educational and Psychological Researches. Baghdad University,. (47): 346-390.

Sam'an, M. (2010). Social Withdrawal Among The Mentally Retarded Children and Its Relations with some of the Variables. Journal of Damascus University, (26). (4), PP. 765-818.

Turner, M (2002). Social phobia relations ship to isolation behavior research and therapy, 30 (9) : 531-538.

Yousef, S. (2011). Those with Social and Emotional Learning Difficulties, Their Specifications, Predicting Them, Caring about them, and their Problems. Dar Almaseera For Publication, Amman, Jordan. 